Hasanah, Fahrurrozi, dan Akmaluddin — Aplikasi Al-Auradul Maraqiyah Maraqitta'limat Berbasis Android

\title{
APLIKASI AL-AURADUL MARAQIYAH MARAQITTA'LIMAT BERBASIS ANDROID AL-AURADUL MARAQIYAH MARAQITTA'LIMAT APPLICATION BASED ON ANDROID
}

\author{
Huswaton Hasanah ${ }^{1)}$, Muh. Fahrurrozi ${ }^{2)}$, dan Akmaluddin ${ }^{3)}$ \\ ${ }^{1,2,3)}$ STMIK Syaikh Zainuddin NW Anjani
}

e-mail: husnh413@gmail.com ${ }^{1)}$,f4.rozi@gmail.com²), hakmaludin30@gmail.com ${ }^{3)}$

\begin{abstract}
ABSTRAK
Yayasan Maraqitta'limat merupakan sebuah yayasan umat islam yang bergerak dibidang dakwah, pendidikan dan sosial kemasyarakatan yang didirikan oleh TGH. Muhammad Zainuddin Arsyad. Seperti kebanyakan organisasi kemasyarakatan umat muslim lainnya, Yayasan Maraqitta'limat memiliki zikir dan doa khusus yang di amalkan untuk anggotanya. Kumpulan zikir dan doa yang dimiliki yayasan maraqitta'limat diberi nama Aurad, yang isinya diambil dari Al-Quran dan Hadits yang tersusun dalam bentuk buku. Proses pembelajaran Aurad sehari-hari diterapkan dengan metode membaca berulang-ulang melalui media cetak dan kemudian dihafalkan. Mengingat saat ini perkembangan teknologi dan informasi telah mempengaruhi perilaku dan gaya belajar seseorang, maka dibutuhkan media belajar yang menarik dan efektif sesuai dengan kebutuhan zaman.sejalan dengan itu maka dibutuhkan aplikasi zikir dan doa mobile berbasis android yang bisa diakses pada Smartphone untuk menunjang kebutuhan perkembangan teknologi saat ini. Aplikasi dzikir dan doa harian ini bertujuan untuk memudahkan anggota Yayasan Maraqitta'limat dalam mempelajari dan menghafal bacaan dzikir dan doa harian yang biasa diamalkan pada yayasan maraqitta'limat secara khusus dan untuk umat muslim secara umum.
\end{abstract}

Kata Kunci: Media Pembelajaran, Aurad, Doa, Android, Smartphone.

ABSTRACT
The Maraqitta'limat Foundation is a Muslim foundation engaged in the field of da'wah, education and social society which was founded by TGH. Muhammad Zainuddin Arsyad. Like most other Muslim community organizations, the Maraqitta'limat Foundation has special zikir and prayers that are practiced for its members. The collection of zikir and prayers owned by the maraqitta'limat foundation is named Aurad, whose contents are taken from the Al-Quran and Hadits which are arranged in book form. The everyday Aurad learning process is applied by reading repeatedly through print media and then memorizing it. Given that currently the development of technology and information has influenced a person's learning behavior and style, an attractive and effective learning media is needed according to the needs of the times. In line with that, an android-based mobile zikir and prayer application that can be accessed on a smartphone is needed to support the needs of technological development. this time. This zikir and daily prayer application aims to make it easier for members of the Maraqitta'limat Foundation to learn and memorize the daily zikir and prayer recitations that are usually practiced at the maraqitta'limat foundation specifically and for Muslims in general.

Keywords: Learning Media, Aurad, Prayer, Android, Smartphone.

\section{PENDAhUluAN}

Y ayasan Maraqitta'limat merupakan sebuah yayasan umat islam yang bergerak dibidang dakwah, pendidikan dan sosial kemasyarakatan yang didirikan oleh TGH. Muhammad Zainuddin Arsyad. Yayasan Maraqitta'limat didirikan pada tahun 1952 dan berdiri sampai sekarang dengan menaungi beberapa lembaga pendidikan formal dan non formal yang berjumlah 126 dan 5 lembaga sosial kemasyarakatan [1]. Seperti kebanyakan organisasi kemasyarakatan umat muslim lainnya, Yayasan Maraqitta'limat memiliki zikir dan doa khusus yang di amalkan untuk anggotanya. Kumpulan zikir dan doa yang dimiliki Yayasan Maraqitta'limat diberi nama Aurad, yang isinya diambil dari Al-Quran dan Hadits yang tersusun dalam bentuk buku. Proses pembelajaran Aurad sehari-hari diterapkan dengan metode membaca berulang-ulang melalui media cetak dan kemudian dihafalkan. Mengingat saat ini perkembangan teknologi dan informasi telah mempengaruhi perilaku dan gaya belajar seseorang, maka dibutuhkan media belajar yang menarik dan efektif sesuai dengan kebutuhan zaman.sejalan dengan itu maka dibutuhkan aplikasi zikir dan doa Mobile berbasis Android yang bisa diakses pada Smartphone untuk menunjang kebutuhan perkembangan teknologi saat ini. Aplikasi dzikir dan doa harian ini bertujuan untuk memudahkan anggota Yayasan Maraqitta'limat dalam mempelajari dan menghafal bacaan dzikir dan doa 
harian yang biasa diamalkan pada yayasan maraqitta'limat secara khusus dan untuk umat muslim secara umum.

\section{STUDI PUSTAKA}

\section{A. Al-Auradul Maraqiyah}

Al Auradul Maraqiyah merupakan doa pusaka yang di susun oleh TGH. Zainuddin Arsyad sebagai pendiri Yayasan Maraqitta'limat pada tahun 1952 dan sampai sekarang Al Auradul Maraqiyah sering diamalkan oleh masyarakat yang ada di kompleks Yayasan Maraqitta'limat [2].

\section{B. Doa}

Manusia pada dasarnya tidak bisa hidup sendirian tetapi membutuhkan orang lain atau sesuatu yang lebih dapat melakukan sesuatu dibandingkan dengan dirinya sendiri. Oleh karena itu manusia tentunya meminta pertolongan. Sebagai seorang muslim maka berdoa adalah suatu yang wajib yang mencirikan bahwa kita menjadi hamba yang lemah yang membutuhkan pertolongan Allah. Doa adalah memohon dan meminta kepada Allah SWT dengan kemurahan hati dan ikhlas tanpa memaksakan supaya doanya terkabul [3].

\section{Smartphone}

Smartphone adalah sebuah telepon yang kegunaan dasarnya sama dengan telepon biasa yang dapat dibawa kemana-mana dan tidak perlu disambungkan dengan kabel, namun memiliki kemampuan tingkat tinggi dengan fungsi yang menyerupai Komputer [4].

Pustaka terkait dengan pengembangan media pembelajaran berbasis android dilakukan juga oleh peneliti sebelumnya, Satria dengan membuat aplikasi ibadah zikir dan doa harian berbasis android. Aplikasi dzikir dan doa harian ini bertujuan untuk memudahkan umat muslim dalam menghafal bacaan dzikir dan doa harian. Metode yang digunakan dalam membuat aplikasi adalah dengan menggunakan metode Multimedia Development Life Cycle. Aplikasi dzikir dan doa harian memiliki fitur pemutar suara yang dapat langsung didengarkan oleh pengguna untuk mempermudah penghafalannya [5]. hal sama juga di lakukan oleh Ramadhan San dengan mengaplikasi Game Edukasi Menghafal Doa-Doa Harian Sebagai Media Belajar Untuk Anak Usia DiniBerbasis Android, Penelitian ini bertujuan untuk membuat sebuah game edukasi berbasis android untuk anak usia dini yang digunakan untuk membantu memudahkan siswa dalam belajar dan menghafal doadoa harian. Penelitian dilakukan di Pendidikan Anak Usia Dini (PAUD) Aisyiyah Pabelan diawali dengan melakukan proses pengamatan dan wawancara untuk melihat cara belajar siswa dalam memahami materi doa-doa harian yang diberikan guru pengajar. Game dibuat sesuai dengan kurikulum yang diajarkan dengan menggunakan software utama Construct 2 yang disajikan dalam bentuk visual 2 dimensi [6]. Pada tahun sebelumnya santoso juga membuat aplikasi pembelajaran doa harian untuk anak usia dini berbasis android yang bertujuan untuk memudahkan anak usia dini dalam mengamalkan doa harian, adapun mentode pengembangan yang digunakan dalam membangun sistem adalah menggunakan metode System Development Life Cycle (SDLC) [7]. Pemanfaatan smartphone sebagai media pembelajaran juga di lakukan oleh Zega dengan membuat media pembelajaran menggunakan sketchware pada materi Good Manufacturing Pratices (GMP) di SMK Pertanian Pembangunan Negeri Lembang dengan tujuan untuk mengetahui kemampuan litterasi visual pada materi GMP di SMK Pertanian Pembangunan Negeri Lembang. Penelitian ini bertujuan untuk mengetahui kelayakan media pembelajaran yang dikembangkan menggunakan sketchware pada materi GMP yang selanjutnya dilakukan penerapan untuk mengetahui kemampuan litterasi visual peserta didik [8]. Hal yang sama juga dilakukan oleh fahrurrozi memanfaatkan smartphone sebagai media pembelajaran untuk Taman Kanak Kanak (TK) yang bertujuan untuk mempermudah mempelajari materi pembelajaran dengan mudah dengan pendekatan Membaca, Menulis dan Menghitung (M3) berbasis multimedia [9].

\section{METODE PERANCANGAN SISTEM}

Adapun metode perancangan sistem yang digunakan untuk membuat aplikasi al-auradul maraqitta'limat adalah menggunakan metode $\mathrm{Wa}$ terfall yang terdiri dari beberapa tahapan yaitu :

\section{A. Pengumpulan Data}

Pengumpulan data diawali dengan pengumpulan semua data yang berkaitan dengan kitab $\mathrm{Au}-$ rad dan kebutuhan perangkat yang digunakan untuk membangun aplikasi. tahapan-tahapan tersebut yaitu : 
1) Wawancara

wawancara dilakukan ke pada pihak yayasan dengan mencatat fitur-fitur yang dibutuhkan dalam pembuatan aplikasi.

2) Studi Pustaka

Studi pustaka merupakan proses pengumpulan data dengan cara mencatat atau membaca dari buku-buku yang berguna dengan pokok permasalahan ataupun refrensi lain. Sebagian besar informasi diambil dari situs-situs internet dan dari bu$\mathrm{ku}$ cetak berupa hasil penelitian orang lain yang berhubungan dengan penelitian ini.

3) Kebutuhan Perangkat Keras

1. Smartphone versi Android

2. Personal Computer atau laptop dengan Procecor I5, RAM 4 Gb, dan Hardisk 250 $\mathrm{Gb}$

4) Kebutuhan Perangkat Lunak

1. Sistem Operasi Nuget Versi Android 7.1.1

2. Sketchware Revolution

3. Photoshop CS 5

4. Sistem Operasi Ubuntu 19.04

5. Nox Emulator

\section{DESIGN SISTEM}

Tahapan design sistem mendeskripsikan gambaran umum tentang rancangan dan proses aplikasi yang dibuat. Use Case Diagram menjelaskan gambaran umum fitur-fitur yang bisa diakses oleh user pada aplikasi, use case diagram dapat dilihat pada Gambar 1. Diagram Activity menjelaskan secara alur program ketika aplikasi dijalankan oleh user, diagram activity dapat dilihat pada Gambar 2. Design graphical user interface (GUI) merupakan sketsa atau rancangan antar muka aplikasi yang akan dibuat pada aplikasi, design GUI dapat dilihat pada Gambar 3 sampai dengan Gambar 9.

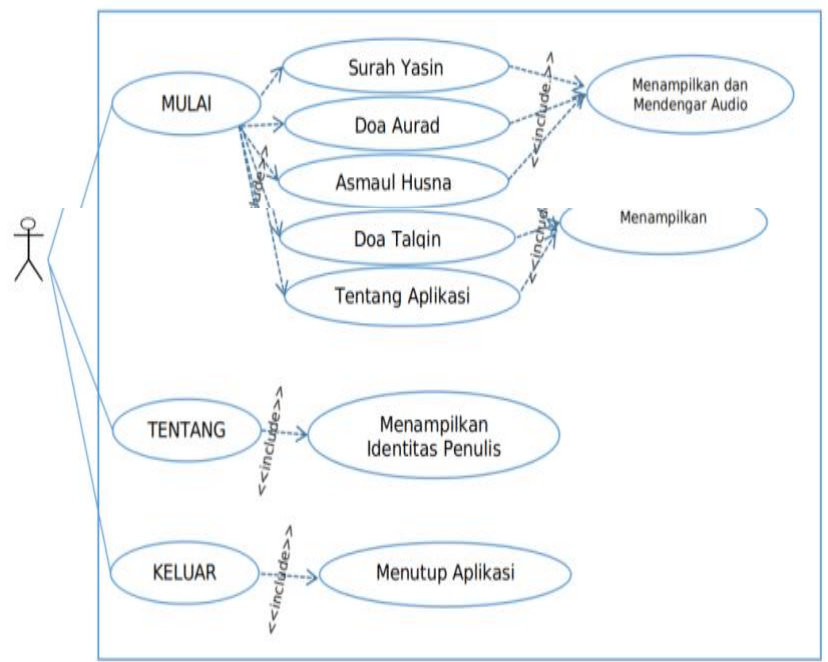

Gambar 1. Use Case Diagram

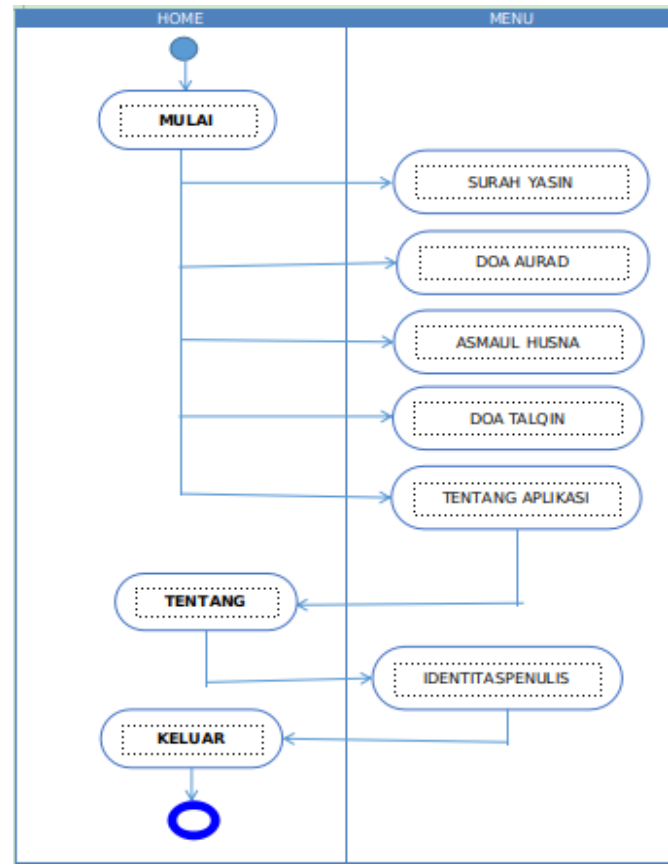

Gambar 2. Activity Diagram

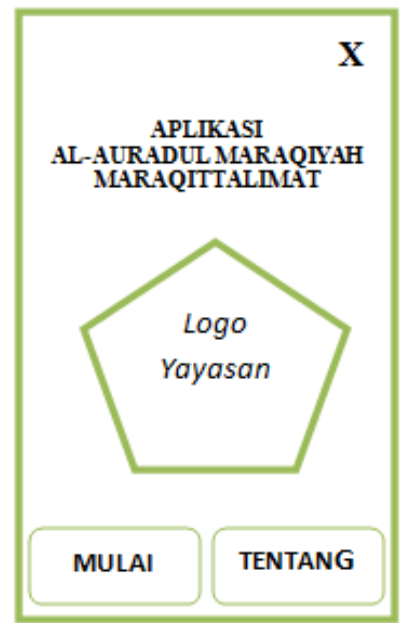

Gambar 3. Tampilan GUI Utama 


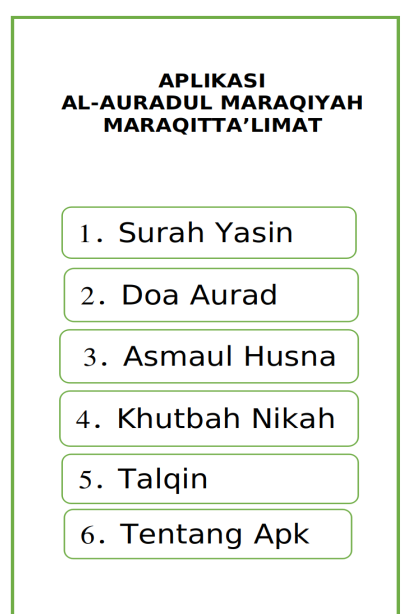

Gambar 4. Design GUI Menu Home

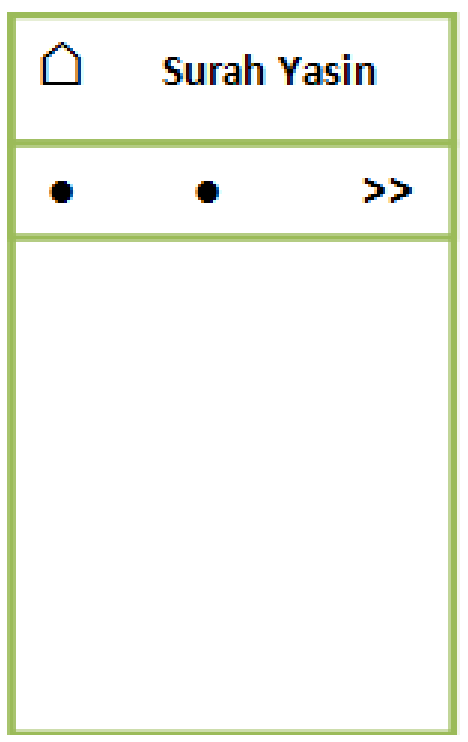

Gambar 5. Design GUI Menu Surah Yasin

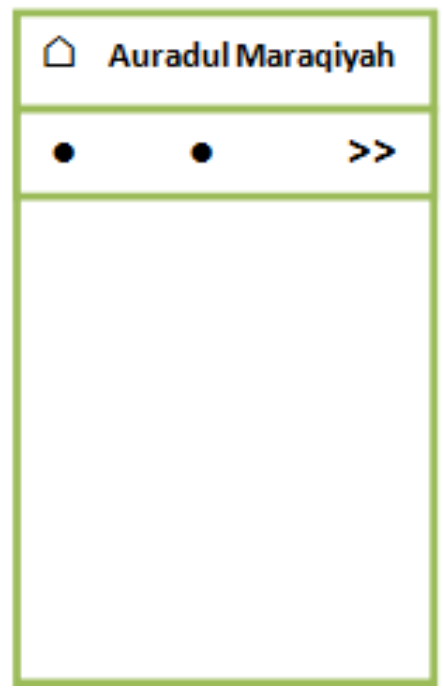

Gambar 6. Design GUI Menu Doa Aurad

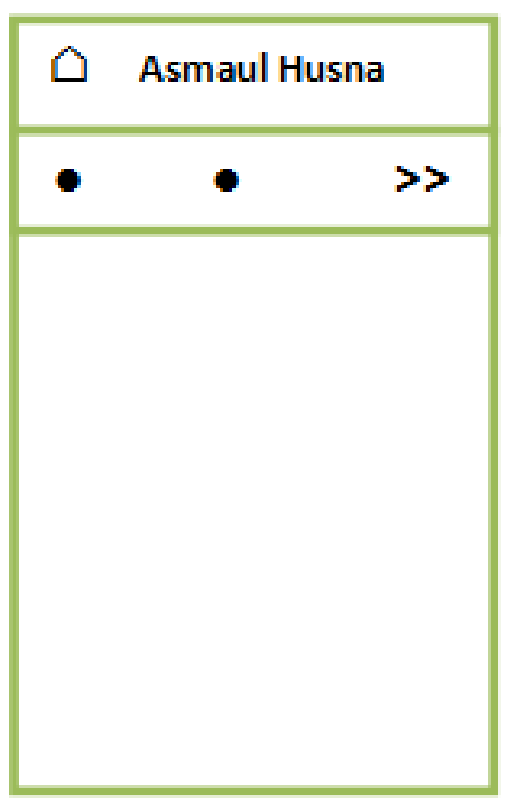

Gambar 7. Design GUI Menu Asmaul Husna

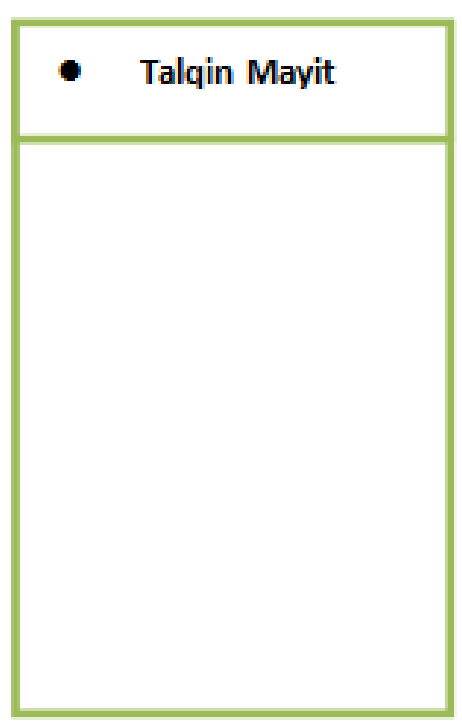

Gambar 8. Design GUI Menu Talqin Mayit

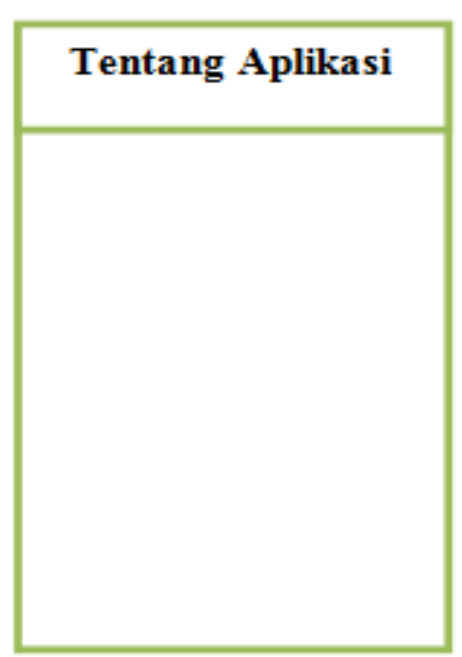

Gambar 9. Design GUI Menu Tentang Aplikasi 


\section{HASIL DAN PEMBAHASAN}

Implementasi program merupakan tahap akhir dari proses pembuatan aplikasi. Hasil dari aplikasi yang telah dibuat, terbagi dalam beberapa bagian sesuai dengan perancangan yang telah dibuat. Adapun tampilan GUI aplikasi yang dibuat terdiri dari :

\section{A. Menu Utama}

Pada GUI menu utama ini terdapat tiga tombol yang dapat digunakan yaitu pertama tombol Mulai digunakan untuk masuk ke Menu Home, kedua yaitu tombol Tentang digunakan untuk menampilkan GUI tentang aplikasi, dan ketiga tombol keluar digunakan untuk keluar dari aplikasi. Tampilan GUI Menu Utama dapat dilihat pada Gambar 10.

\section{B. Мепи Ноте}

Pada GUI Menu Home terdapat enam menu untuk mengakses menu Surah Yasin, Do'a Aurad, Asmaul Husna, Talqin Mayit dan Tentang Aplikasi. GUI Menu Home dapat dilihat pada Gambar 11.

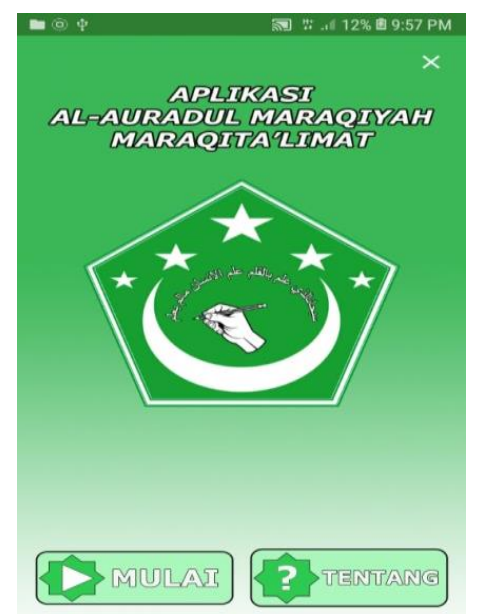

Gambar 10. Design GUI Menu Utama

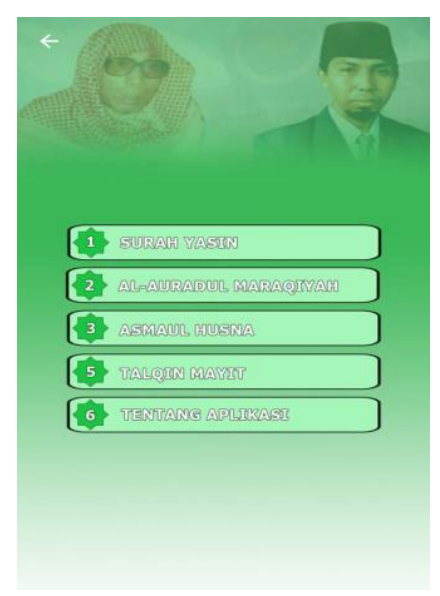

Gambar 11. Design GUI Menu Home

\section{Menu Surah Yasin}

Pada menu ini menampilkan Surah Yasin yang dilengkapi Mode Malam dan Memutar Audio. GUI Menu Surah Yasin dapat dilihat pada Gambar 12.

D. Menu Doa Aurad

Pada menu ini menampilkan Doa Auradul Maraqiyah yang dilengkapi dengan huruf arab, mode malam dan memutar audio. GUI Menu Doa Aurad dapat dilihat pada Gambar 13.

\section{E. Menu Asmaul Husna}

Pada menu ini akan menampilkan Asmaul Husna yang dilengkapi dengan huruf arab, mode malam dan memutar audio. GUI Menu Asmaul Husna dapat dilihat pada Gambar 14.

\section{F. Menu Doa Talqin}

Pada menu ini akan menampilkan Doa Talqin yang dilengkapi dengan huruf arab, mode malam dan memutar audio. GUI Menu Doa Talqin dapat dilihat pada Gambar 15.

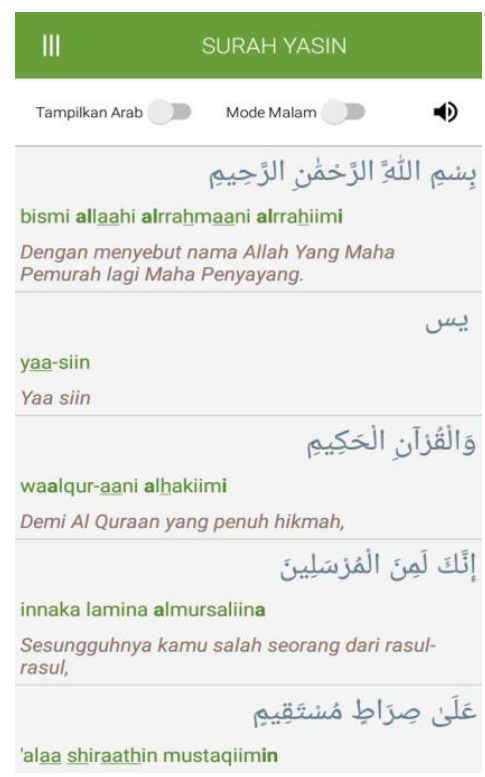

Gambar 12. Design GUI Menu Surah Yasin 


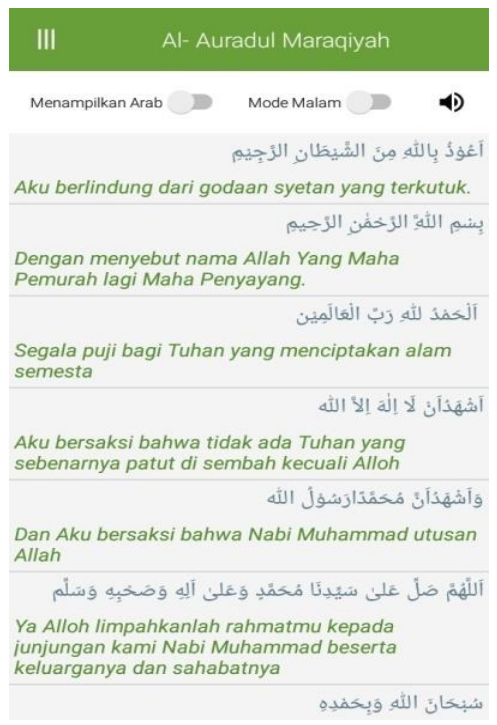

Gambar 13. Design GUI Menu Doa Aurad

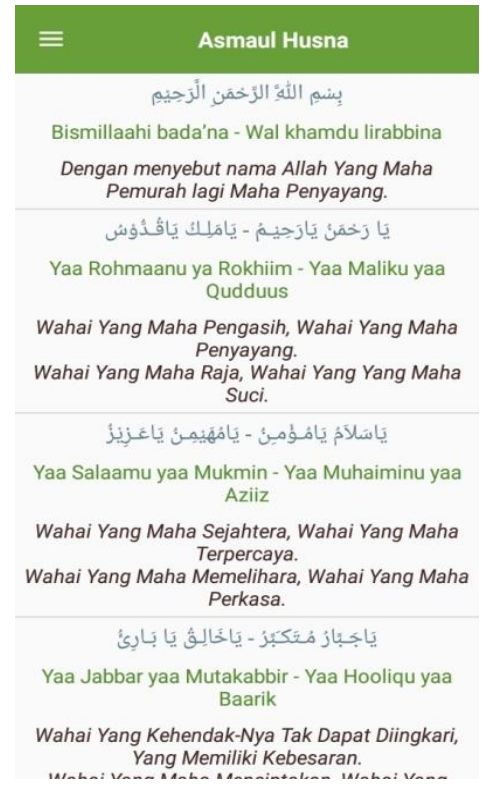

Gambar 14. Design GUI Menu Asmaul Husna

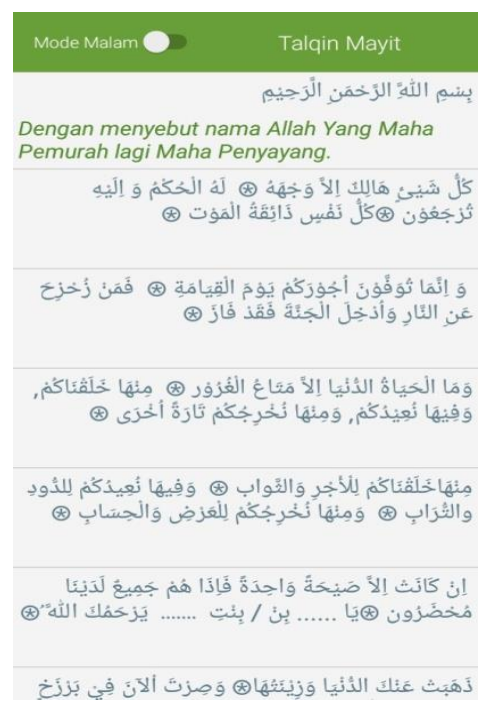

Gambar 15. Design GUI Menu Talqin Mayit

\section{G. Menu Tentang}

Pada menu ini menampilkan tentang aplikasi yang dikembangkan. GUI Menu Tentang dapat dilihat pada Gambar 16.
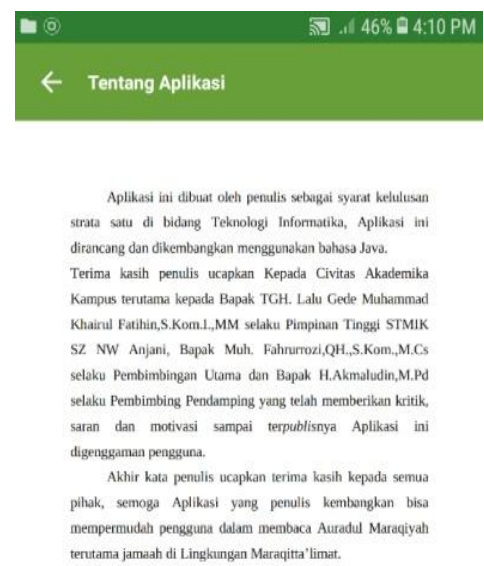

Gambar 16. Design GUI Menu Tentang Aplikasi

\section{KESIMPULAN}

Aplikasi Al-Auradul Maraqitta'limat dapat menjadi alternatif media pembelajaran berbasis android yang bisa digunakan pada smartphone untuk membantu umat muslim dalam menjalankan ibadahnya khususnya bagi warga Yayasan maraqitta'limat dan umat muslim pada umumnya. Dengan adanya aplikasi maraqitta'limat berbasis android diharapkan bisa meningkatkan semangat belajar generasi muda yang kebanyakan tidak bisa lepas dari perangkat smartphone dalam segala aktivitasnya.

\section{DAFTAR PUSTAKA}

[1] Compasiana, (2015, 26 Juni). Perkembangan YAYASAN MARAQITTA'LIMAT SAAT INI, https://www.kompasiana.com/sahlan/5500f26ba33311 0d17510613/perkembangan-yayasan-maraqitta-limatntb-saat-ini.

[2] Jayadi, "Sejarah Pondok Pesantren Maraqitta'limat. Sejarah Islam Lombok", Sinar Mentari, Surabaya, 2011.

[3] Vanela Y., "Doa Sebagai Metode Psikoterapi Islam Untuk Kesehatan Pasien di Rumah SAkit Umum Daerah (RSUD) Dr.Hi.Abdul Moeloek", Skripsi, Fakultas Dakwah Ilmu Komunikasi Institut Agama Islam Negeri Bandar Lampung, Bandar Lampung : 2016.

[4] Zulkarnain, "Sistem Aplikasi Al-Auradul Maraqiyah Maraqitta'limat berbasis android menggunakan Adobe Flash", Skripsi, STMIK Syaikh Zaniuddin NW Anjani : Lombok Timur, 2019.

[5] Satria, E., Tresnawati, D., Saepuloh, C., Rancang Bangun Aplikasi Ibadah Dzikir Dan Doa Harian Ber- 
basis Android, urnal STT-Garut, ISSN : 2302-7339

Vol. 14 No. 22017.

[6] Ramdhan S.T., Yasin, A.F., "Game Edukasi Menghafal Doa-Doa Harian Sebagai Media Belajar Untuk Anak Usia Dini Berbasis Android", Jurnal Emitor, ISSN 2541-4518, Vol.18, No. 02, 2018.

[7] Santoso, B., Febriyani, O., Aplikasi Pembelajaran Doa Harian Untuk Anak Usia Dini Berbasis Android, Jurnal Informatika Universitas Pamulang, ISSN 25411004 Vol. 2, No. 4, 2017.

[8] Zega, Anisa pengembangan media pembelajaran menggunakan sketchware pada materi good manufacturing pratices di smk pertanian pembangunan. Skripsi. Universitas Pendidikan Indonesia : Jakarta. 2019

[9] Fahrurrozi, M., Indra, K.L.P, Khairunnazri, Media Pembelajaran M3 (Membaca, Menulis, Menghitung) Berbasis Multimedia untuk Anak usia Dini, TEKNIMEDIA : ISSN 2722-6271, Vol. 1, No. 1, 2020. 